Document downloaded from:

http://hdl.handle.net/10251/157195

This paper must be cited as:

Del Hoyo-Meléndez, JM.; Carrión-Ruiz, B.; Riutort-Mayol, G.; Lerma, JL. (2019). Lightfastness assessment of Levantine rock art by means of microfading spectrometry. Color Research \& Application. 44(4):547-555. https://doi.org/10.1002/col.22372

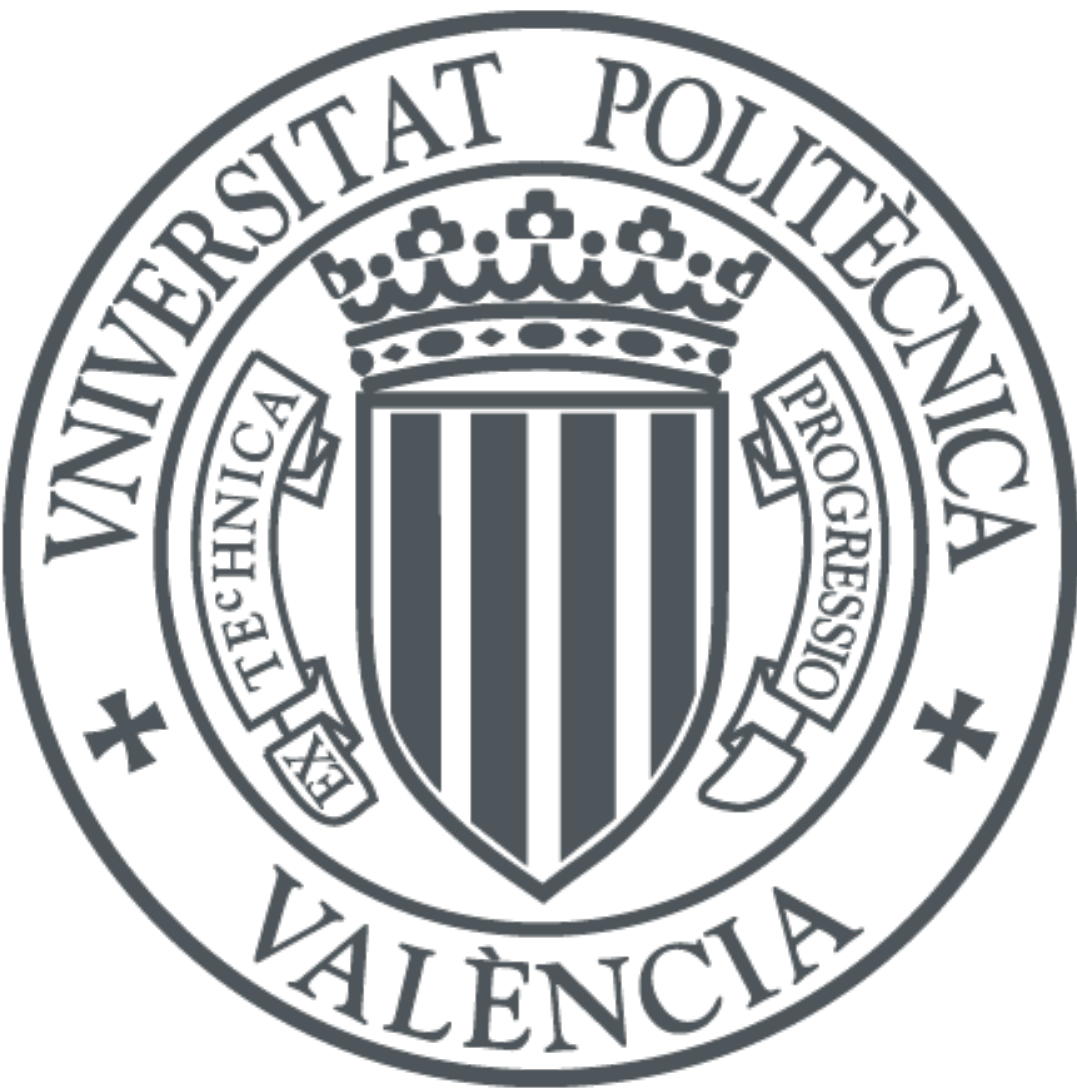

The final publication is available at

https://doi.org/10.1002/col.22372

Copyright John Wiley \& Sons

Additional Information

This is the peer reviewed version of the following article: del Hoyo-Meléndez JM, Carrión-Ruiz B, Riutort-Mayol G, Lerma JL. Lightfastness assessment of Levantine rock art by means of microfading spectrometry. Color Res Appl. 2019;44:547 555, which has been published in final form at https://doi.org/10.1002/col.22372. This article may be used for noncommercial purposes in accordance with Wiley Terms and Conditions for Self-Archiving. 


\title{
LIGHTFASTNESS ASSESSMENT OF LEVANTINE ROCK ART BY MEANS OF MICROFADING SPECTROMETRY
}

\author{
Julio M. del Hoyo-Meléndez, Berta Carrión-Ruiz, Gabriel Riutort-Mayol, José Luis Lerma
}

\begin{abstract}
The documentation of archaeological sites requires the adoption of non-destructive techniques to safeguard the unique legacy coming from prehistoric periods. This paper tackles the assessment of the lightfastness properties on a rock art site to determine the behaviour of motif's colour deterioration over time in Remigia Cave, Castellón (Spain), which is considered part of a UNESCO World Heritage Site. The measurements were performed using a micro-fade testing (MFT) device to analyse the spectral characteristics and the ageing properties of the colourant system and various substrates on site. Two scenarios have been identified depending on whether the lightness $\left(L^{*}\right)$ parameter of the rocky substrate changes or not in relation with the painted motifs. If the substrate remains stable without any change, red motifs containing iron oxide pigments will become more visible. If the substrate becomes lighter, the pigments will experience similar changes. Therefore, the contrast between paintings and support will be considerably enhanced.
\end{abstract}

KEY WORDS: Photosensitivity, Pigments, Colour degradation, Spanish Levantine Rock art, Documentation

\section{Introduction}

In recent years, conservation and protection of rock art has drawn the attention of professional archaeologists and researchers. Preventive conservation has been established as one of the most suitable tools for an effective protection of cultural heritage objects. Therefore, preserving and controlling the threats that affect our cultural heritage are a priority line in both management and research. Mitigating these effects is expected to be a priority for the cultural heritage sector and the societies around the world ${ }^{1,2}$.

On the one hand, it is possible to classify threats in a practical way by a distinction between manmade and natural threats. However, two different categories can be defined, those threats having an immediate effect in a short time and those having slow and cumulative effects. Palumbo (2002) noted that slower natural effects such as erosion, material decay, and pests could be very destructive. On the other hand, once identified and classified threats and damage affecting heritage monuments, it is important to develop reliable protection plans for rock art paintings. There are several reports and studies that identified the importance of preventive conservation of rock art sites. For example, the International Council on Monuments and Sites (ICOMOS) published a report that identifies the dangers that affect our cultural heritage and suggests procedures for different types of threats promoting the maintenance, monitoring and promotion of traditional and modern preventive technologies ${ }^{4}$.

Rock art is one of the most ill-treated cultural heritage due to its open-air location. In particular, rock art paintings of the Mediterranean basin on the Iberian Peninsula World Heritage were declared World Heritage by UNESCO in 1998. Prehistoric Levantine rock art paintings normally occur on vertical walls inside shelters and they are subject to deterioration mainly by weathering conditions, lichens, vandalism and specific local elements, which accelerate their degradation. In addition, the moisture conditions and the geological features are some of the local factors that can cause an increase of the deterioration ${ }^{5,6}$. Furthermore, Díez-Herrero et al. (2009) have demonstrated that sunlight can have adverse effects on these type of paintings due to thermal and photochemical degradation. Thermal deterioration is caused by the non-uniform distribution of temperature between the rock's surface and the core, causing fissures or damages in the rock. On the other hand, the rock art painting system is formed by patina / pigment / binder / substrate 
that may vary over time due to photochemical degradation experienced by their components. In addition, the presence of oxalates encrustations on the substrate can also cause alterations making it more whitish. Several authors have reported on oxalate layers and how they affect rock art ${ }^{8-10}$

Frequently, the rock support is very important in the configuration of rock art paintings. The threedimensional (3D) documentation is the basis for a better understanding of rock art and serves as a starting point for diagnosing how to conserve and prevent its degradation ${ }^{11-15}$. In addition, techniques such as infrared, ultraviolet or multispectral photography and digital image processing are contributing to achieve an improvement in the visibility and enhancement of the paintings in a non-invasive way ${ }^{16-20}$.

In particular, the Cova Remigia rock art shelter, Castellón is part of the Spanish Levantine rock art; the paintings are located in a complex opened-air rock site and contains a large variety of motifs. Thus, it is an ideal case study due to the degradation that is suffering. In addition, it is being studied in several research projects to document and determine right preservation measures at different levels. Molada-Tebar, Lerma, and Marqués-Mateu (2017) employed rigorous colorimetric techniques to record properly the colour of rock art paintings using digital photography. Del Hoyo-Meléndez et al. (2015) studied the photo-stability of a couple of areas containing red and black pigments on a rock art scene and revealed how useful the physical information about the photostability of a pigment is for better understanding of archaeological sites. However, the latter research is presented as a preliminary study to validate the micro-fade testing (MFT) technique. This paper enhance the knowledge of this promising research area by making a contribution that will help to make informed decisions for future archaeological site preservation.

The MFT technique can help us to extrapolate changes in colour over time. Moreover, MFT is a technique that provides not only information about the current state of the material, but also gives information about the potential colour changes that the material may experience because of uncontrolled and long light exposure. Whitmore, Bailie, and Connors developed the MFT technique in the late 1990s $(1999,2000)$. The instrument combines reflectance spectroscopy and accelerated ageing and has been extensively used in the field of conservation and restoration of cultural heritage ${ }^{25-28}$. Therefore, it can be considered a useful technique for studying the surface characteristics and the radiation behaviour of features. In recent years, the study of pigments has become more relevant, since it is possible to know about the chemical composition, the origin of materials, the mixtures preparation and the photostability of the pigments ${ }^{8,22,29-31}$. Thanks to the research of some authors on the characterization of Levantine rock art pigments today we know more about the pigments used for this type of paintings. Although, it is not known how the colour will change over time. The main objective of this study is to analyse the impact of direct solar irradiation in the Cova Remigia rock art paintings by undertaking in situ lightfastness measurements by means of the MFT technique. Previous campaigns revealed that the paintings receive direct sunlight around two three hours daily, early in the morning, depending on the time of the year ${ }^{22}$. For this purpose, black/red painted areas and their surroundings were selected in order to obtain reliable data from the pigmented zones. Furthermore, the results can be considered complementary to other pigment studies previously conducted at Cova Remigia or on other archaeologically related sites ${ }^{30}$.

\section{Materials and methods}

\section{MFT measurements}

MFT experiments were performed using a device developed by researchers at the Krakow National Museum and at the Faculty of Chemistry of the Jagiellonian University ${ }^{32}$ and it is a variation of the original prototype designed by ${ }^{23}$. This instrument consists of a high-power light source, a $0^{\circ} / 45^{\circ}$ geometry optical setup, and a VIS reflectance spectrometer. The high power light source employed is a HPLS 30-04 solid-state plasma light source (LIFI) from Thorlabs (New 
Jersey, USA). The system uses fiber optics to provide non-contact measurement and detection. The size of the illuminated spot is about $0.5 \mathrm{~mm}$, while the estimated intensity measured at the spot was 6.0 Mlx. The spectrometer used is an Ocean Optics (Florida, USA) Jaz miniature device. The first visible reflectance spectrum was used as reference and subsequent spectra were collected every $10 \mathrm{~s}$ for a total testing time of $600 \mathrm{~s}$. The integration time was 100 milliseconds and 10 spectra were averaged. The MFT setup contains a high power light source that illuminates a small area and determines the size of the sample, an optical setup and a VIS-spectrometer (Fig. 1).

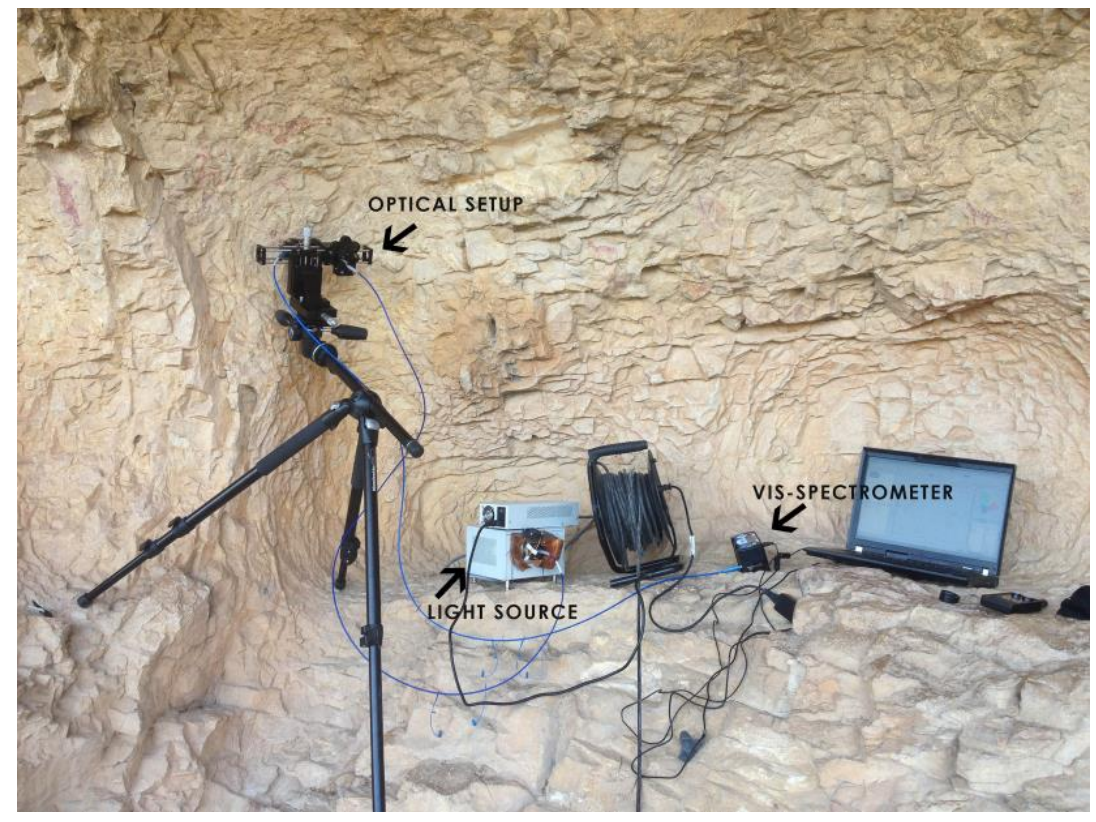

Figure 1. MFT setup used for the light stability evaluation of rock art paintings.

MFT measurements provide discretely collected curves that represent the potential light colour changes over a long exposition time. These functional observations can be considered as artificial curves where the longitudinal axes (X-axis) represent an artificial scale of time and the response axis ( $Y$-axis) represent the Delta $\mathrm{E}^{*}$ values. However, the MFT instrument may lead to sub-optimal outcomes when it works on the distinctive rock art surfaces. Hence, it is important to note that the rock substrate may also present a glossy layer that can introduce a specular reflection component producing unstable subsequent spectra if recorded in real time. In fact, the MFT instrument is very sensitive to movement and glossy surface effects. Therefore, in some cases extremely large fluctuations in Delta $E^{*}$ values can be registered during measurements. In order to remove these fluctuations and for a better an easier interpretation of the curves, a smoothing procedure is recommended (Ruppert et al. 2009). Moreover, as in-situ MFT data acquisition on rock art shelters cannot be easily isolated from ambient solar radiation, MFT measurements can be affected by non-uniform and small amounts of external illumination, causing non-linear distortions along the MFS measurement. These distortions can cause that basic and simple smoothing procedures yield with some non-desired features, such as curves neither being increasingly monotonic nor reaching stabilization over time. Furthermore, these distortion effects in addition to large fluctuations, can result in smoothed curves that do not have a zero-valued colour degradation at the first time measurement. These properties are supposed to affect the fading curves. In order to take into account these likely artefacts, some constraints are recommended to be included for smoothing. In the work presented herein, we have added three constraints to the smoothing procedure by means of modelling the MFT measurements as Gaussian processes with derivative information (Riihimäki and Vehtari, 2011): a) being zero at the first time point; b) being curves always increasingly monotonic; and c) reaching a stabilization level at the end.

\section{Data analysis}


The International Commission on Illumination (Commission Internationale de l'Éclairage) details that CIE standard illuminants are used in colourimetry to compute the tristimulus values of reflected or transmitted object colours under specified conditions of illumination ${ }^{33}$. The Standard illuminant D65 has been approved by CIE and ISO and should be used in all colourimetric calculations to represent average daylight illumination conditions. Moreover, the CIE standard colourimetric observer is representative of the colour-matching properties of observers ${ }^{34}$. Regarding this, the illuminant and observer combination used was D65 and 2 degree, respectively.

Colour changes were evaluated using the CIELAB 1976 standard space colour as some authors claimed that this standard is the most convenient for studying archaeological sites ${ }^{21}$. This colour space is composed by three values: $L^{*}$ (lightness of the colour), $a^{*}$ (position between red and green), $b^{*}$ (position between yellow and blue). Thus, colour differences were calculated using de difference colour formula $\Delta \mathrm{E}^{\star}$ ab (1) (CIE76).

$$
\Delta \mathrm{E}^{*}=\left[\left(\mathrm{L}_{2}-\mathrm{L}_{1}\right)^{2}+\left(\mathrm{a}_{2}-\mathrm{a}_{1}\right)^{2}+\left(\mathrm{b}_{2}-\mathrm{b}_{1}\right)^{2}\right]^{1 / 2}(1)
$$

On the other hand, by using the Blue Wool (BW) standards, it is possible to estimate the lightfastness of a dyed fabric or paint ${ }^{35}$, with BW 8 being the most and BW 1 the least stable. Due to the sensitivity range of MFT technique, higher stability than BW 3 is considered approximately stable to light. The reaction rates of the surveyed areas are compared to those observed for BW standards 1-3 under the same experimental conditions since they are still considered the only reasonable reference materials for evaluating the lightfastness of unknown colorants. Therefore, the colour differences on both pigments and substrate are obtained and compared with the BW standards 1, 2 and 3 under the same conditions (Table 1). In particular, the fading rates of the tested areas are compared to the ones obtained for the BW standards after a 10-minute test ${ }^{36}$.

Table 1. MFT results obtained for BW standards 1-3 at the same conditions employed during the testing of the rock art scene.

\begin{tabular}{cc} 
& $\Delta E^{*}$ ab \\
Reference Material & (CIE76) \\
\hline BW 1 & 5.5 \\
\hline BW 2 & 3.0 \\
\hline BW 3 & 0.5
\end{tabular}

\section{Results}

MFT measurements were conducted on 18 samples (Table 2). The purpose was to study the spectral characteristics and the ageing properties of the colourant system and various substrates. Therefore, measurements were taken in two pre-selected areas of the rock art site with painting motifs available, corresponding to two areas of the rock art site (Figs. 2 and 3). The evaluated areas were those containing dark red pigments, red pigment areas, and rocky support areas with different shades close to the paint spots. The measured points were different from those measured in ${ }^{22}$, they were not found in the same panel. In such a way, the number of samples would increase with the aim to getting a bigger corpus of data considering the difficulty of measuring on site in the shelter.

In this case, we can affirm that the samples are measured on a rock-base substrate, sometimes covered on top with pigments depicting the rock art motifs. However, it is necessary to distinguish two types of samples between the painted ones. In fact, painted samples are divided in two: a) red-dotted areas; and b) areas with dark red pigments. The first sampling area (Area 1) is around $30 \mathrm{~cm} \times 30 \mathrm{~cm}$, and hosted the first $13^{\text {th }}$ measurements (Fig. 2). The second area (Area 2), with measurements $14^{\text {th }}$ up to $18^{\text {th }}$ covers approximately an area of $40 \mathrm{~cm} \times 40 \mathrm{~cm}$ (Fig. 3). It is 
important to note that the roughness of the support, full of irregularities, increases the difficulty at the time of arranging the measurements; ones setup the MFT device, the measurement itself lasts around 10-15 minutes. Therefore, each measurement on site must be thought carefully to optimise the resources and minimise the time.

Table 2. Summary of measurements samples on site.

\begin{tabular}{|c|c|c|c|}
\hline Samples & Description & $\Delta E^{*}{ }_{a b}(C I E 76)$ & Classification \\
\hline 1 & $\begin{array}{l}\text { Human figure, area of torso, red } \\
\text { painted and light brown substrate }\end{array}$ & 3.2 & Red painting \\
\hline 2 & Orange substrate & 0.5 & Limestone \\
\hline 3 & $\begin{array}{l}\text { Dark red paintings over orange } \\
\text { substrate }\end{array}$ & 1.1 & Dark red painting \\
\hline 4 & Dark red paintings & 1.0 & Dark red painting \\
\hline 5 & $\begin{array}{l}\text { Red pigment applied on orange- } \\
\text { pink substrate }\end{array}$ & 0.4 & Red painting \\
\hline 6 & $\begin{array}{l}\text { Red zone boar's rump next to an } \\
\text { area of orange-pink substrate }\end{array}$ & 2.2 & Red painting \\
\hline 7 & Red zone on middle figure & 1.2 & Red painting \\
\hline 8 & Orange substrate & 1.9 & Limestone \\
\hline 9 & Light brown substrate. & 6.2 & Limestone \\
\hline 10 & Substrate flaked & 8.9 & Limestone \\
\hline 11 & Orange substrate & 0.5 & Limestone \\
\hline 12 & $\begin{array}{l}\text { Red zone surrounded by orange } \\
\text { substrate }\end{array}$ & 1.6 & Red painting \\
\hline 13 & Light orange substrate & 4.9 & Limestone \\
\hline 14 & Red painted zone & 0.4 & Red painting \\
\hline 15 & Red painted zone & 1.1 & Red painting \\
\hline 16 & Orange substrate & 1.6 & Limestone \\
\hline 17 & Dark red paintings pigments & 0.2 & Dark red painting \\
\hline 18 & Red painted zone & 0.3 & Red painting \\
\hline
\end{tabular}




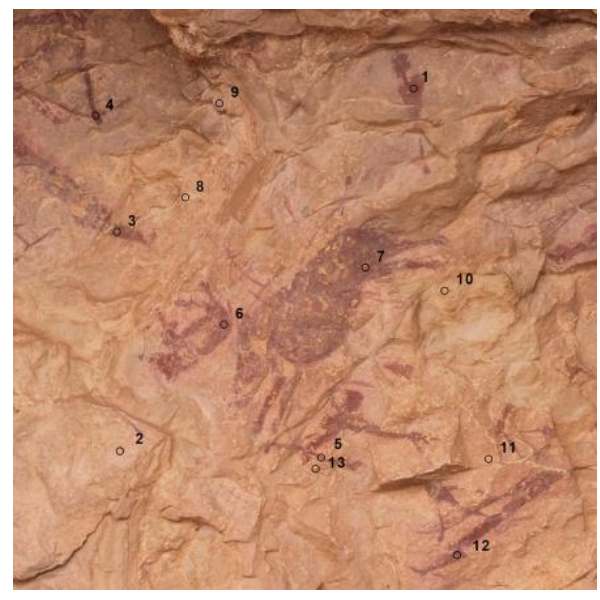

Figure 2. Measurements located in Area 1.
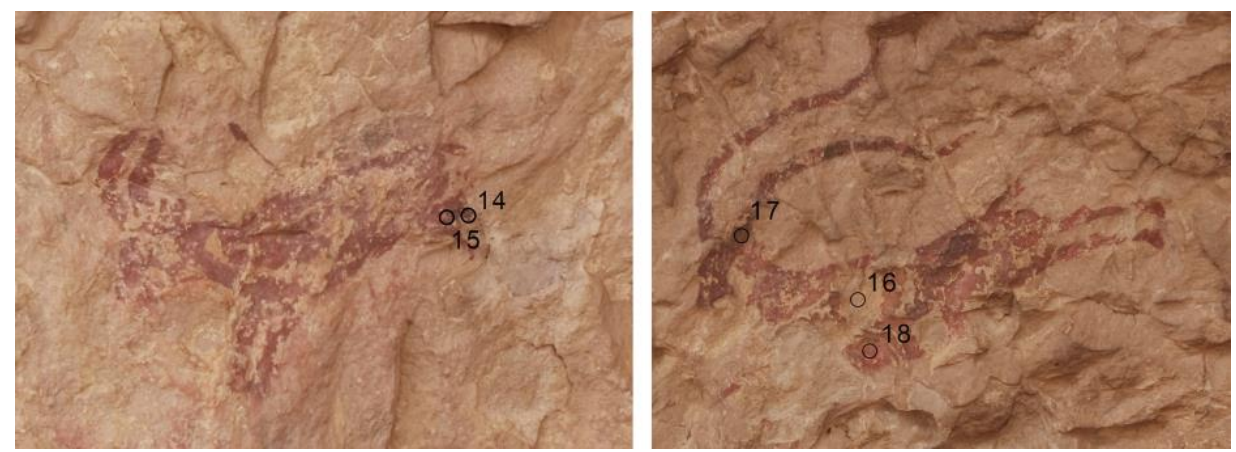

Figure 3. Measurements located in Area 2.

The results are shown grouped by the type of material analysed, i.e. the measurements have been grouped into three different graphs according to the type of surface measured: samples with dark red pigment (Fig. 4), red paintings (Fig. 5) and support (Fig. 6). Each of the figures represents the colour change that the material has undergone throughout the lighfastness measurement. Further, it is important to take into account which magnitude of the colour change is discernible by the naked eye. The colour change is noticeable for people when $\Delta \mathrm{E}^{*}$ (Eq. 1) is higher than 2.3 for the CIE76 colour space. Thus, we will be considering differences of colour below three units, which are hardly perceptible by the human eye ${ }^{37,38}$.

The observed curves are represented in dotted-line style and their corresponding smoothed ones are represented in a continuous-line style. Smoothing the original observations is needed in order to remove the large fluctuations in the data, as well as local tendencies likely caused by external illumination effects, as reported in Section 2. This can be seen in the plots where the smoothed curves tend to follow the global tendency avoiding to follow local effects. Only the raw MFT data is presented by dotted lines in Fig. 4; Figs. $5 \& 6$ present the smoothed curves to ease the assessment.

The results obtained in dark red sampling areas allow us to confirm that the change of colour remains quite low. In addition, the colour change is kept constant. There are no sharp slope changes in the curves, which means that the colour variation is maintained around one over time.

The results obtained in the red sampling points show that the colour changes in a similar way as the dark red pigments, except for two Points, 1 and 6, as they show a change of colour next to 3 , being this value the highest colour change value obtained in red painted samples.

The results obtained on the support are those that reveal major variety of colour change over time. In fact, 3 out of 7 present $\Delta E^{*}>3$, corresponding to Points 9,10 and 13 , all of them 
corresponding to pale samples of limestone. Points 2, 8, 11 and 16 of orange support present $\Delta \mathrm{E}^{*}<3$

On the other hand, MFT results allowed us to identify four different groups based on their response to light irradiation, using the BW standards as reference: Group 1, very high sensitivity (>BW1); Group 2, high sensitivity (BW1-BW2); Group 3, moderate sensitivity (BW2-BW3); and Group 4, low sensitivity (<BW3).

Firstly, Group 1 contains two very high sensitive zones associated with the substrate including a light brown (Point 9) and a flaked (Point 10) limestone area, which exhibited fading rates that exceeded the one recorded for BW1.

Secondly, Group 2 includes a high sensitive sample that corresponds with a light orange area of the limestone substrate (Point 13) which registered a $\Delta E$ value that is between the one recorded for BW1(5.5) and BW2 (3.0) and was therefore classified as highly sensitive.

Thirdly, moderately sensitive samples of Group 3 correspond to Points 1, 3, 4, 6, 7, 8, 12, 15 and 16. Two out of these points present the highest colour changes of the group, next to 3 . They are the red Points 6 and 1. The rest of the samples are a dark red paint (Points 3 and 4), red paint (Points 7, 12 and15) and finally, orange substrate zones (Points 8 and 16).

Finally, there are six points in the Group 4, namely 2, 5, 11, 14, 17 and 18, that exhibited changes comparable to the one recorded for BW3. Points 2 and 11 consisted of areas of orange substrate, while Points 5, 14 and 18 were red colorant systems containing iron oxide pigment applied over an orange substrate similar to the one found in Points 2 and 11. Point 17 was a zone of dark red pigment

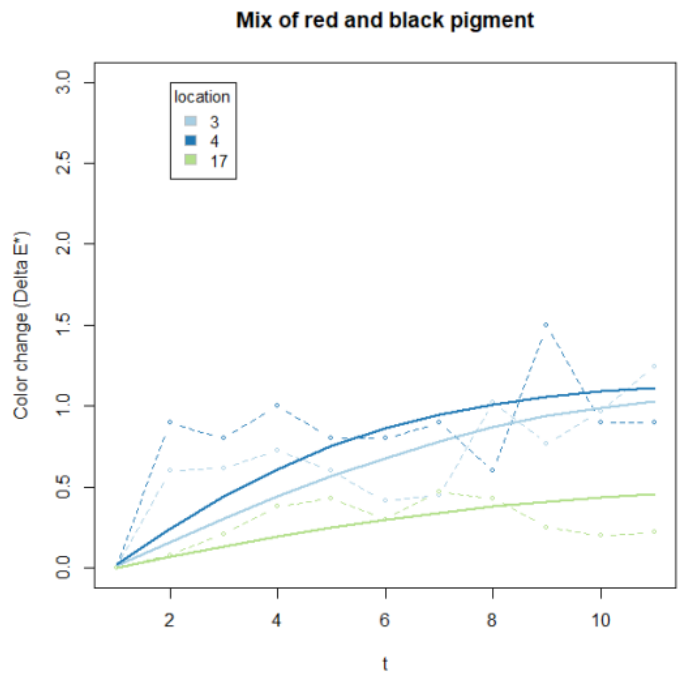

Figure 4. Results for various dark red pigments. 


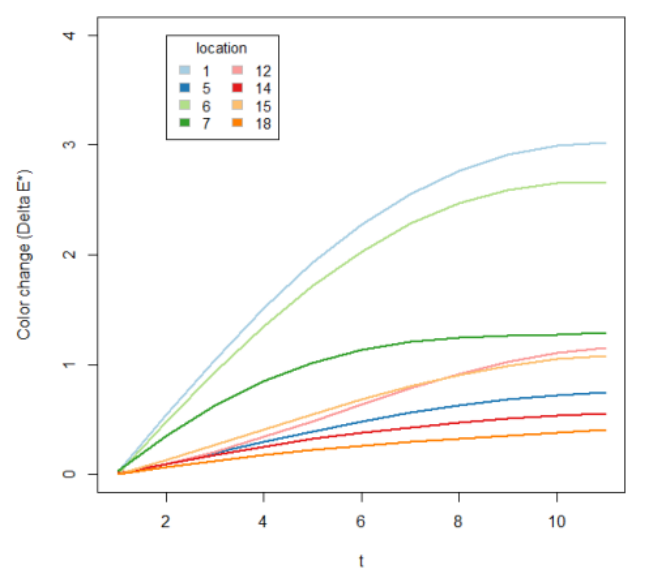

Figure 5. Results for red pigment zones.

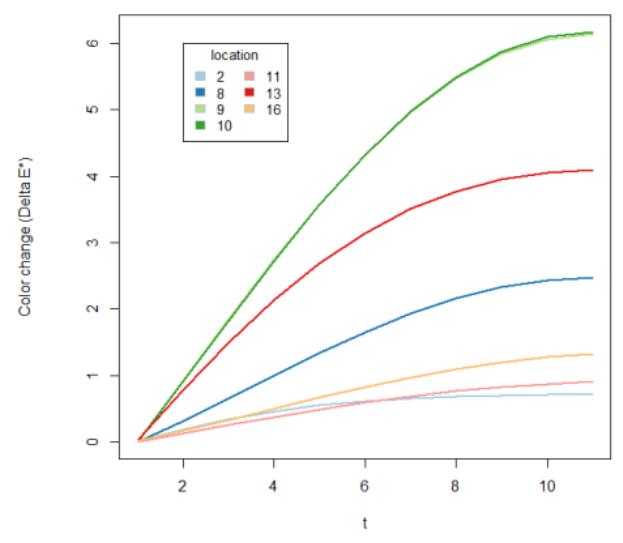

Figure 6. Results for the rock substrate.

Besides, the direction of the colour changes can be better appreciated by plotting the CIE colourimetric parameters $a^{*}$ and $b^{*}$. For the very high sensitive areas (substrate), it was observed that there was no change in the lightness parameter $L^{*}$. Therefore, the change is exclusively defined by variations in redness $\left(a^{*}\right)$ and yellowness $\left(b^{*}\right)$ parameters, and points that show moderate-low sensitivities have low variability in their colourimetric parameters. An example of such a plot is shown in Fig. 7. This plot can be visually divided into two parts. In the upper area (A), the changes experienced by the support samples are presented. On the other hand, the area below (B) shows the changes experienced by pigments. Hence $b^{*}$ parameter is higher in support samples.

Points 9,10 and 13 are those reaching colour differences above 2.3 and thus they are perceivable. It is interesting to note that although the substrate areas related to Points 9,10 and 13 have different colours, the direction of change is similar to all of them; in all these cases the redness parameter decreases. Moreover, the red painted area (Point 1) shows a change in the opposite direction moving towards the red as the test progresses. This is in agreement with previous MFT results that showed how an area painted with black pigment became darker as a result of irradiation with high intensity light ${ }^{22}$. As shown in Fig. 7, the $a^{*}$ and $b^{*}$ parameters barely vary in the samples of Group 3 and 4 except for Points 1 and 6 (as it is already stated above). 


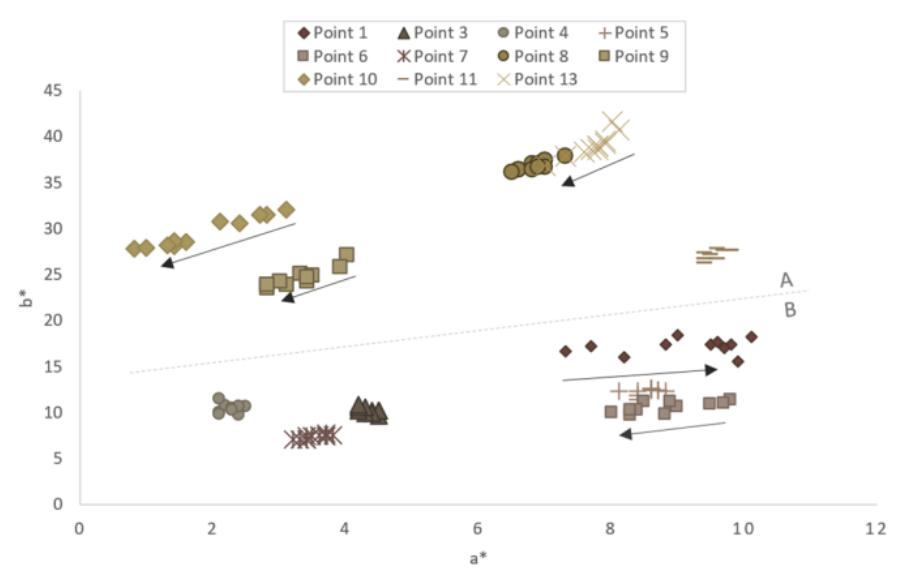

Figure 7. Plot of yellowness $\left(b^{*}\right)$ versus redness $\left(a^{*}\right)$ parameter for MFT measurements conducted on the substrate $(A)$ and red painted pigments $(B)$.

\section{Discussion}

MFT results on the substrate indicate that it is likely that the concentration of iron oxide pigment in this area was low and the dominating effect of the substrate was still being observed, but to a lesser degree due to the presence of the red pigment. Colourant systems containing relatively higher concentration of pigment are known for producing a light-stable system when applied to the rock ${ }^{22}$.

The presence of a black pigment in dark red samples could explain the lower degree of change in Points 3, 4, 7 and 17 due to the protective effect of the black light-absorbing pigment. The higher stability of Point 7 is explained by the higher concentration of iron oxide pigment in this area resulting in a lesser detectable change due to higher coverage of the rock by the pigment.

Classifying the results according to the sensitivities obtained for the Blue Wool scale, four groups are obtained. Groups 1 and 2, containing the most sensitive zones (less stable), are composed by rock substrate samples. It is important to note that these samples are taken in pale areas of rock due to composition or damages. These samples have colour changes higher than 3, i.e. they can be detected by human eye. Finally, groups of results that correspond to the most stable points (Group 3 and 4) contain areas of orange rock substrate, red colorant and dark red pigment in which probably black is the prevailing pigment. On the other hand, according to the trend of the red/green $\left(a^{*}\right)$ and yellow/blue $\left(b^{*}\right)$ values, it is interesting to highlight that the rock support in Points 9 and 10 will change, the parameters of redness, yellowness and lightness will be lower, so the colour will be darker. In addition, dark red pigments tend to show a decrease in darkness (lower $\left.L^{*}\right)$. Thus, if the rock substrate has a dark tone, this will result in less contrast, meaning that the paintings can be lost due to lack of contrast.

Reaching this point, it can be stated that two scenarios have been identified. In the first scenario, $1^{\text {st }}$ Scenario, the rock substrate shows no change in the lightness $\left(L^{*}\right)$ parameter. If this is the case, a red painted zone that shows an increase in redness $\left(\mathrm{a}^{*}\right)$ will become more visible under natural ageing conditions. Similarly, a dark red painted zone that experiences a decrease in reflectance (lower $L^{*}$ ) with ageing will become more discernible as a result of ageing. In the second scenario, $2^{\text {nd }}$ Scenario described in Fig. 7, the pigments experience a similar change to the one described in the $1^{\text {st }}$ Scenario, while the substrate becomes lighter with time. This is even a more favourable situation as the contrast is considerably enhanced.

Since red pigments are most likely Fe-based, the result obtained for the red zones was somehow expected, because it is known that Fe-based pigments generally exhibit good lightfastness properties i.e. they are very stable after long exposures to light. In fact, Druzik (2010) analysed Fe-based pigments samples by means MFT and colour changes were not detected. This is the case of points with higher concentration of iron oxide pigment resulting in a high stability of the point. Based on the results presented by del Hoyo-Meléndez et al. (2015), the red pigment area 
exhibited low sensitivity to light showing more stable than the black pigment area, that was found to be very sensitive. Nevertheless, analysing the results obtained, it looks as if the rock substrate is having a dominating effect in the ageing tests. In other words, when the pigment concentration is low, the change is greater, e.g. Points 1 and 6 . In contrast, if the thickness of the paint layer is higher (more concentration of pigment), we will see the opposite effect. Therefore, this is something to consider when making the simulation of future colour changes. MFT results only offer physical information; characterization of pigments cannot be done with this technique. In this sense, other techniques such as EDXRF or Raman can complement the MFT technique and enrich the analysis of pigments behaviour over time in painted rock art motifs.

After applying this non-invasive lightfastness technique, it is rather difficult to identify colour differences in the two tested areas. When analysing rock art paintings, we deal with a system formed by patina / pigment / binder / substrate. Therefore, this system varies in each single spot, so extending this research to other motifs of the same shelter, or even other related rock art archaeological sites would be of great interest and crucial to confirm whether or not this technique is highly recommended for long-term documentation and monitoring. After extensive lightfastness analysis, it will be possible to confirm whether urgent measures need to be considered for better preservation and conservation.

Finally, it is important to consider that a smoothing procedure (with inclusion of constraints) has led to more reliable and realistic smoothed curves. In case the application of these constraints was not available for the users, at least a basic and simple smoothing technique is highly recommended in order to remove fluctuations. Additionally, careful interpretations are also recommended in order to detect visually possible systematic artefacts remaining in the smoothed curves.

\section{Conclusion}

The MFT technique has been employed for lightfastness analysis on a series of rock art systems in Cova Remigia (Castellon, Spain). MFT is confirmed as a useful technique to know how susceptible the rock/paint are to light and how much they are likely to fade over time. Subtle differences were detected at measurements and were attributed to other chemical components (e.g. calcite) that interfere with the signal coming from the pigment producing slight changes. Moreover, MFT results showed that areas containing higher concentration of pigment were more stable to light in comparison to areas where the pigment was applied using a thinner and transparent application. This was explained by the significant contribution of the rock substrate on the overall result. A stabilization effect was found essential when dark red pigments were analysed. This is due to the high absorption effect of the dark pigment that results in the overall stabilization of the rock/paint system. Everything indicates that the lighter colour of the rock will improve the contrast between the rock/paint system.

Future research contemplates the assessment of darker areas of substrate in order to see if we can detect a change that will result in a negative outcome (i.e. less contrast). In addition, it would be interesting to increase the number of samples of paintings found in several archaeological sites in order to compare the results and enrich the data interpretation. Finally, a combination of meteorological data and hours where the paintings receive direct sunlight are necessary to estimate the equivalency of the exposure delivered by the instrument with that received naturally.

\section{ACKNOWLEDGEMENTS}

The authors also would like to thank the Generalitat Valenciana for providing access to the site during the measurement campaign. Fruitful comments from the Archaeologist Dra. Esther LópezMontalvo are also gratefully acknowledged. The authors acknowledge the research project HAR2014-59873-R from the Spanish Ministerio de Economía y Competitividad for providing financial support. 


\section{References}

1. Cassar M, Brimblecombe P, Nixon T, et al. Technological Requirements for Solutions in the Conservation and Protection of Historic Monuments and Archaeological Remains.; 2001.

2. Vileikis O, Cesaro G, Santana Quintero M, van Balen K, Paolini A, Vafadari A. Documentation in World Heritage conservation: Towards managing and mitigating change - the case studies of Petra and the Silk Roads. J Cult Herit Manag Sustain Dev. 2012;2(2):130-152. doi:https://doi.org/10.1108/20441261211273635.

3. Palumbo $\mathrm{G}$. Threats and Challenges to the Archaeological Heritage in the Mediterranean. In: Management Planning for Archaeological Sites. ; 2002:3-12.

4. ICOMOS. ICOMOS WORLD REPORT 2000 ON MONUMENTS AND SITES IN DANGER. https://www.icomos.org/risk/world_report/2000/risk2000.htm. Published 2000. Accessed October 25, 2017.

5. Giesen MJ, Ung A, Warke PA, Christgen B, Mazel AD, Graham DW. Condition assessment and preservation of open-air rock art panels during environmental change. $J$ Cult Herit. 2014;15(1):49-56. doi:10.1016/j.culher.2013.01.013.

6. Bednarik RG. The use of weathering indices in rock art science and archaeology. Rock Art Res. 2012;29(1):59-84.

7. Díez-Herrero A, Gutiérrez-Pérez I, Lario J, et al. Analysis of potential direct insolation as a degradation factor of cave paintings in Villar del Humo, Cuenca, Central Spain. Geoarchaeology. 2009;24(4):450-465. doi:10.1002/gea.20274.

8. López-Montalvo E, Villaverde V, Roldán C, Murcia S, Badal E. An approximation to the study of black pigments in Cova Remigia (Castellón, Spain). Technical and cultural assessments of the use of carbon-based black pigments in Spanish Levantine Rock Art. J Archaeol Sci. 2014;52:535-545. doi:10.1016/j.jas.2014.09.017.

9. Hernanz A, Gavira-Vallejo JM, Ruiz-López JF. Calcium oxalates and prehistoric paintings. the usefulness of these biomaterials. J Optoelectron Adv Mater. 2007;9(3):512-521.

10. Hernanz A, Ruiz-López JF, Gavira-Vallejo JM, Martin S, Gavrilenko E. Raman microscopy of prehistoric rock paintings from the Hoz de Vicente,Minglanilla, Cuenca, Spain. J Raman Spectrosc. 2010;41(11):1394-1399. doi:10.1002/jrs.2582.

11. Barnett T, Chalmers A, Díaz-Andreu M, et al. 3D Laser Scanning For Recording and Monitoring Rock Art Erosion. Int Newsl Rock Art. 2005;41:25-29. doi:10.1063/1.2756072.

12. Ruiz J, Sebastian M, Quesada E, et al. 4D arte rupestre. 2014:371.

http://www.4darterupestre.com/.

13. Domingo I, Villaverde V, López-Montalvo E, Lerma JL, Cabrelles M. Latest developments in rock art recording: Towards an integral documentation of Levantine rock art sites combining 2D and 3D recording techniques. J Archaeol Sci. 2013;40(4):1879-1889. doi:10.1016/j.jas.2012.11.024.

14. Lerma JL, Cabrelles M, Navarro S, Seguí E. Modelado fotorrealístico 3D a partir de procesos fotogramétricos : láser escáner versus imagen digital scanning versus digital image. Cuad Arte Rupestre. 2013;6(May 2010):85-90.

http://cuadernosdearterupestre.es.

15. Lerma JL, Cabrelles López M, Navarro Tarín S, Galcerá Ustero S. Documentación 3D y visualización multimedia de la Cova del Parpalló (Gandia). Virtual Archaeol Rev. 2010;1(2):123-127. doi:10.4995/var.2010.4701.

16. Carrión-Ruiz B, Blanco-Pons S, Lerma JL. Digital image analysis of the visible region through simulation of rock art paintings. In: Proceedings of the 8th International Congress on Archaeology, Computer Graphics, Cultural Heritage and Innovation 
“ARQUEOLÓGICA 2.0.” ; 2016:169-175. doi:10.4995/arqueologica8.2016.3560.

17. Domingo I, Carrión B, Blanco S, Lerma JL. Evaluating conventional and advanced visible image enhancement solutions to produce digital tracings at el Carche rock art shelter. Digit Appl Archaeol Cult Herit. 2015;2:79-88. doi:10.1016/j.daach.2015.01.001.

18. Fredlund G, Sundstrom L. Digital infra-red photography for recording painted rock art. Antiquity. 2007;81(January):733-742. doi:10.1017/S0003598X00095697.

19. Cerrillo-Cuenca E, Sepúlveda M. An assessment of methods for the digital enhancement of rock paintings: The rock art from the precordillera of Arica (Chile) as a case study. $J$ Archaeol Sci. 2015;55:197-208. doi:10.1016/j.jas.2015.01.006.

20. Robert E, Petrognani S, Lesvignes E. Applications of digital photography in the study of Paleolithic cave art. J Archaeol Sci Reports. 2016;10:847-858. doi:10.1016/j.jasrep.2016.07.026.

21. Molada-Tebar A, Lerma JL, Marqués-Mateu Á. Camera characterization for improving color archaeological documentation. Color Res Appl. 2017;(May). doi:10.1002/col.22152.

22. del Hoyo-Meléndez JM, Lerma JL, López-Montalvo E, Villaverde V. Documenting the light sensitivity of Spanish Levantine rock art paintings. ISPRS Ann Photogramm Remote Sens Spat Inf Sci. 2015;II-5/W3(September):53-59. doi:10.5194/isprsannals-II5-W3-53-2015.

23. Whitmore PM, Pan X, Bailie C. Predicting The Fading of Objects: Identification of Fugitive Colorants Through Direct Nondestructive Lightfastness Measurements. J Am Inst Conserv. 1999;38(3):395-409. doi:10.1179/019713699806113420.

24. Whitmore PM, Bailie C, Connors SA. Micro-fading tests to predict the result of exhibition progress and prospects. Stud Conserv. 2000;45(Supplement 1):200-205.

25. Ford B. Non-destructive microfade testing at the National Museum of Australia. AICCM Bull. 2011;32(1):54-64. doi:10.1179/bac.2011.32.1.008.

26. del Hoyo-Meléndez JM, Mecklenburg MF. A survey on the light-fastness properties of organic-based Alaska Native artifacts. J Cult Herit. 2010;11(4):493-499.

doi:10.1016/j.culher.2010.01.004.

27. Druzik JR. Evaluating the Light Sensitivity of Paints in Selected Wall Paintings at the Mogao Grottoes: Caves 217, 98, and 85. In: Conservation of Ancient Sites on the Silk Road. The Getty. Los Angeles: The Getty Conservation Institute; 2010:457-463.

28. Ford B, Druzik J. Microfading: The state of the Art for Natural History Collections. Collect Forum. 2013;27(January 2016):54-71.

29. López-Montalvo E, Roldán C, Badal E, Murcia-Mascarós S, Villaverde V. Identification of plant cells in black pigments of prehistoric Spanish Levantine rock art by means of a multi-Analytical approach. A new method for social identity materialization using chaõÃne opeÂratoire. PLoS One. 2017;12(2). doi:10.1371/journal.pone.0172225.

30. Roldán C, Murcia-Mascarós S, Ferrero J, et al. Application of field portable EDXRF spectrometry to analysis of pigments of Levantine rock art. $X$-Ray Spectrom. 2010;39(3):243-250. doi:10.1002/xrs.1254.

31. Roldán García C, Villaverde Bonilla V, Ródenas Marín I, Murcia Mascarós S. A unique collection of Palaeolithic painted portable art: Characterization of red and yellow pigments from the Parpalló Cave (Spain). PLoS One. 2016;11(10):1-22. doi:10.1371/journal.pone.0163565.

32. Lojewski T, Thomas J, Golab R, Kawalko J, Lojewska J. Light ageing with simultaneous colorimetry via fibre optics reflection spectrometry. Rev Sci Instrum. 2011;82(7). doi:10.1063/1.3606645.

33. CIE. CIE standard illuminants. CIE Colorimetry - Part 2: Standard Illuminants for Colorimetry. http://cie.co.at/index.php?i_ca_id=484. Accessed October 25, 2017. 
34. CIE. CIE standard observers. CIE Colorimetry - Part 1: Standard Colorimetric Observers. http://cie.co.at/index.php?i_ca_id=483. Accessed October 25, 2017.

35. Arkivprodukter. The Blue Wool Standards. www.arkivprodukter.no. Accessed November 23, 2017.

36. Bacci M, Cucci C, Mencaglia AA, Mignani AG, Porcinai S. Calibration and Use of Photosensitive Materials for Light Monitoring in Museums: Blue Wool Standard 1 as a Case Study. Stud Conserv. 2004;49(2):85-98. http://www.jstor.org/stable/1506899.

37. ISO 12647-2. INTERNATIONAL STANDARD for the production of half-tone colour. 2004;2004.

38. Mahy M, Van Eycken L, Oosterlinck A. Evaluation of Uniform Color Spaces Developed after the Adoption of CIELAB and CIELUV. Color Res Appl. 1994;19:105-121.

\section{AUTHOR BIOS}

Julio M. del Hoyo-Meléndez

Julio M. del Hoyo-Meléndez holds a PhD in science and conservation of cultural heritage from the Department of Conservation and Restoration of Cultural Heritage of the Polytechnic University of Valencia, Spain. In 2011, he joined as a Research Scientist the Laboratory of Analysis and Non-Destructive Investigation of Heritage Objects of the National Museum in Krakow, Poland. As of January 1, 2017 he holds the position of Head of Laboratory and Head of the National Research Center for Cultural Heritage, both based at the National Museum in Krakow. He is the Editor-inChief of the Journal of the American Institute for Conservation since November 2014.

\section{Berta Carrión-Ruiz}

Technical Engineer in Topography (2011) from the Polytechnic University of Valencia (UPV). Realization of Final Year Project about architectural heritage 3D modelling and sketching. Engineer in Geodesy and Cartography (2014) from the UPV. She is currently working on the improvement of the rock art documentation process by means of multispectral images. She is a researcher of GIFLE since 2016. The main lines of research are the development of new multispectral and scientific image analysis.

\section{Gabriel Riutort-Mayol}

He received a MSc in Biostatistics and is currently a PhD student in Statistics at the Department of Statistics and Operations Research at the Universitat de València (Spain). He is currently a technical researcher at the Universitat Politècnica de València (Spain) where he works on applied statistics in the fields of image processing, photogrammetry, and environmental sciences, with a special interest in the use of Bayesian Hierarchical Models.

José Luis Lerma

Professor in the Department of Cartographic Engineering, Geodesy and Photogrammetry at the Universitat Politècnica de València, Spain. Specialist in documentation of cultural heritage with imaging, range and multispectral sensors. Coordinator of the PhD Programme in Geomatics Engineering and Editor-in-Chief of the Virtual Archaeology Review. 